\title{
COMPARING VIRTUAL LEARNING TECHNIQUES UPON TECHNOLOGY ACCEPTANCE AND STUDENT ENGAGEMENT IN DIFFERING CLASSROOM ENVIRONMENT
}

\author{
Tasfia Bari and Munther Abualkibash \\ Eastern Michigan University, College of Technology, USA
}

\begin{abstract}
With divergent educational processes brought forth through the unforeseen circumstances such as a global pandemic, students have become obligated to pursue virtual means towards obtaining their education. Therefore, this study seeks to review the different formats of virtual learning processes and methodologies that are currently made available to students based on student and user perception and technology adoption efforts. Through comparative analysis efforts identifying synchronous, hybrid and asynchronous virtual educational standards across multiple publications and understanding technology acceptance models (TAM) and theories such as perceived usefulness, it is understood that virtual learning efforts which pursue an asynchronous methodology are more comparable in contrast other formats.
\end{abstract}

\section{KEYWORDS}

Virtual Learning, Technology Acceptance Models, Technology Adoption, Education, Perceived Ease of Use.

\section{INTRODUCTION}

With the impact of technology becoming increasingly prevalent in its influence within the classroom, the necessity for technological intervention and integration has become vital in educational development throughout the world. This was especially noticeable during the inception of the COVID-19 pandemic (Ortega et al, 2020). As families were obligated to optimize safety and precautionary measures over daily living practices and routines, many educational institutions have had to scramble to find alternative methods of supplying and supporting educational and learning processes for their students who were now obliged to stay home and maintain their safety and well-being (Chou \&amp; Liu, 2005). Given the unprecedented nature of the situation at hand, educational institutions often find themselves taking additional expenditures to accommodate such purchasing electronic tools and finding webbased resources and literature to provide their students. Educators, regardless of their familiarity with the e-learning options and platforms were tasked with transferring their daily educational processes to a virtual classroom and meeting atmosphere on short notice (Dyson \&Barreto, 2003). Digital interventions and alternatives have become key in supporting such shifts and different platforms which had not necessarily catered to education were not re-structuring their resources to accommodate the needs of society.

While necessary shifts and changes in education were brought forth through digital means the user's perception of education were no longer at the forefront in terms of deciding how and which tools were best suited to provide education. If students are required additional support 
outside of the classroom, those resources became temporarily unavailable. School predetermined budgets were re-allocated in terms of expenditures which catered to the shift in need. Different students had to be accommodated based on their family's resources and socioeconomic status (Evans et al, 2004). While others, based on their physiological and developmental needs, had to be accommodated in other manners. Overall to withstand delays which would prevent or disturb the development of students, it is most imperative educational systems to maintain a certain degree of cognizance of technology acceptance and adoption. Such approaches bring forth both areas of deficit and progress as the structure of the alternative educational processes did hold some benefit for different abled learners. Therefore, reviews different formats of virtual learning processes and methodologies that have been made available to students based upon different student and user perception and technology adoption efforts in recent approaches.

Within the United States of America, public education classrooms are already facing vast discrepancies in terms of classroom sizes, and financial resources, expenditures and diversity (Teo, 2011). For students who are considered to be developmentally disabled, differently abled and or atypical in terms of their learning process such areas of discrepancy are only further exasperated. Sitting in large classrooms in which the ratio of students to educators are largely offset due to budgetary constraints and limitation of resources, can often hinder a differently abled student's progress and development in terms of their educational growth (Phungsuk \& Vanija, 2020). Therefore the mandatory shifts brought forth through the pandemic could pose some benefit in terms of providing learners of different capacities and capabilities with the opportunity to achieve their full potential while also exemplifying to educators and administrators that different techniques and approaches to teaching could prove effective in the future and in the long run.

The growth and expansion of e-learning has often been exhibited in areas of educational supplementation and support. In previous years and analyses, e-learning has been established through software and tools which could help students based on their grade level and educational development based on attributes of their progress such as their reading level and math level (Owusu-Mensah, 2019). If a student were to struggle within a certain area of the curriculum, educators would refer families to purchase text or software in the format of CD disks which they could install and provide their child with practice outside of school (Rientes et al, 2014). These similar educational tools were also made available to students within the classroom in their free time and if additional support programs outside the classroom were made available. Students who received additional support in supplementing certain skills through tutoring and educational software use were noted to progress their deficits by integrating key concepts into a student's learning by providing new, different and creative ways of teaching the same concepts as that which was covered in the course materials (Tagoh \& Abakah, 2014).

With such occurrences, educators as well as families began to note that supplemental tools, programs and software were providing a newfound element of support for learners who were otherwise struggling to attain the same information as their peers. Students who may have been diagnosed with learning disabilities such as dyslexia, attention deficit hyperactivity disorder (ADHD), Autism and or dyscalculia were now receiving additional support in manners which could not otherwise be provided to them through a traditional classroom environment. Students with dyslexia, struggle with the perception of certain words and numbers which often make it challenging to understand at the same pace and perspective other neurotypical peers within their class (Van Raaij \& Schepers, 2008). Similarly, those who were diagnosed with dyscalculia faced such challenges with numerical symbols and computation.

Students with ADHD have challenges with attending in classroom settings which feature tasks that require students to sit for long periods of time without shifts in stimuli to keep them 
preoccupied and engaged (Whorisky, 2003). Whereas students diagnosed within the Autism spectrum, may exhibit a variety of different challenges in regard to their perception of a neurotypical educational curriculum. This is due to the notion of Autism having a spectrum of different deficits ranging in terms of verbal-behavioral development. Rather than relocating such students into special education classrooms which perhaps given their skillset, were beneath their acquired education level, they were provided the chance to maintain their seat within their classroom while also receiving the additional support which they required. Therefore, closing the gap in classroom diversity (Goo, 2014).

As global education efforts have grown to encompass tools such as Zoom, Google Teams, Udemy and Masterclass to continue their curriculum, the newfound format of schooling has also shifted to accommodate the differences (Faisal et al, 2021). Classroom sizes, albeit reflective of traditional, physically present classrooms were maintained in terms of the expected ratio of teachers to students, the hours in which classes occur have shifted to provide students with a break and accommodate family schedules as well. Therefore, students who would otherwise have challenges sitting and attending in a classroom setting for long periods of time now have the opportunity to get up and rationalize their daily lesson and curriculum at a pace which is more comfortable for them to digest (Owusu-Mensah, 2019).

Additional benefits brought forth by e-learning includes consistency. By providing a scheduled time, location and insight into a lesson plan through email exchange and online learning platforms, students and their families can better prepare for their daily lesson at their own pace rather than one which is established based on a physical classroom setting which the needs of multiple students must be considered (Evans et al, 2004). Therefore, students who are on the autism spectrum benefit from such changes as they are allowed expectations, routine and structure within their daily classroom experience (Lei et al, 2018). This is especially pertinent given that individuals on the Autism spectrum are often known to have rigidity in regard to sudden or newfound changes. Similarly, the personalization features brought forth by e-learning also provides students who are differently abled with the opportunity to better customize their individual learning experience based on what makes them comfortable rather than a classroom at large. This can be observed through different setting adjustments such as sound and lighting. As well as location and placement of where they are sitting. By being able to tune in from home, students may feel less pressure in terms of seating and social obligations which are often enforced within the physical classroom environment and school settings (Joseph et al, 2013).

\section{TeChnology ACCePtance Methodology}

With such benefits brought forth through e-learning platforms, the users of such technologies, which in this case would be the students, the acceptance and therefore the overall adoption of technology is increased. In terms of perceived usefulness (PU), items such as a login screen, video camera and microphone are all tools which allow a user to perceive the important terms pertaining to the adequate and appropriate process occurring within their tasks (Davis, 1993). For example, on both zoom the login screen may be accessed in multiple ways. Especially if the user already has the software installed unto their computer and is accessing a specific meeting as a guest. Amongst the two different ways that the login screen can be accessed, a user may perceive it as simply logging in and entering the meeting link in the search bar. However, if they are invited by someone else, the user can access the same meeting or specific meeting by simply clicking on the link provided for them in the email which invited them to the event itself. This is a format of perceived usefulness (PU) as the multiple entrance options conveys to the user that the accessibility features of the technology are making their job or their busy day easier to navigate (Kerzic et al, 2019). 
Another example of PU utilization in educational systems includes the video camera feature of the Zoom or Microsoft Teams video conferencing software(s). The video camera on/off option is both prominently featured in both the initial screen as well as the screens displayed upon entering the meeting. If users do not feel comfortable having their cameras on as they enter the meeting, they can simply turn it off and turn it on later after the events begin or as they need to appear. Lastly, usage of PU is also noted in the microphone features of a Zoom or Microsoft Teams engagement or call as users have the option to have their microphone on or off as they enter a call or throughout the call as needed. This is both beneficial to the host of the virtual conference or meeting as well as the guest as it can eliminate unnecessary background noises and distractions for the other attendees. In terms of Perceived Ease of Use (PEOU), items can seem easy or accessible in its usage based upon the efficacy it conveys to the user.

This was observed in Bandura's theory of self-efficacy which suggested that users are more inclined to engage with a tool or process based on how autonomous the user felt through its usage. Therefore, both Bandura's theory of self-efficacy and Davis's theory of PEOU, which came afterwards, are dependent upon the user's psychological determination and their own notion of independence from engaging with that tool and in their efforts towards completing a certain task at hand (Bandura, 1977).

Such formats of PEOU can be observed in a variety of interactions. For example, reflecting back upon our Zoom and Microsoft Teams example, one could say that the multiple login feature that allows a user to enter a call-in different manner is useful because of the versatility it provides (Hubbard \& Bailey, 2018). However, when revisiting this item and construct from the perspective of "ease" we can observe how this specific item also provides the user with a sense of autonomy in their digital meetings or engagement. Social norms and expectations aside, by allowing the user to have the option to enter a meeting at their own ease, they are provided with an aspect of accessibility that allows them more opportunities to organize their approach towards the technology itself.

For the theory of planned behavior, in terms of partaking in digital classrooms and e-learning platforms, it is inferred that a relevant and important behavior worth noting is classroom engagement. This behavior is particularly interesting as it has shifted to encompass a digital environment and now useful tools such as the ability to mute one's camera and microphone can also deter them from engaging within the classroom or meeting overall (Rientes et al, 2013). While such features do provide the user with a sense of autonomy in regard to how accessible they want to be within a classroom environment, it can also deter their engagement with the overall conversation. The tools that provide them with ease can also hamper the discussion and their engagement within the meeting (Rovai et al, 2019).

While the extent of engagement and how much is necessary by the attendees may vary in terms of the size of the meeting, the context of the situation or discussion and those in attendance, in a classroom setting specifically one would anticipate that the educator would want their students to participate to the best of their capabilities. Therefore, the behavior that will be observed as the "dependent variable", otherwise known as the item, that will reflect the behavior under this model will be one which emphasizes user engagement. Thus the "unmute" feature will be observed as this variable. By unmuting a user's microphone or video, the user or student is allowing a sense of presence and access within the virtual classroom environment.

\section{Comparative Analysis}

Amongst the three primary methods utilized in most virtual learning environments today, different approaches benefit different educational institutions based on their own unique 
structural processes and development. With the rise of unforeseen circumstances such as the COVID-19 global pandemic, education administrators have had to redevelop their approaches towards curating alternative classroom environments. Synchronous learning environments provide students with a live approach towards their education. By providing students with realtime lectures and content engagement opportunities, it mimics a format of live, in-person classroom environments, allowing natural interactions between users participating in the overall discussion (Ruggieri et al, 2013). Benefits brought forth by this format includes allowing the lecturer or instructor the opportunity to engage with their students and address any questions and concerns they may have right away. It also promotes student engagement by providing an alternative method of attendance for those who may issue in appearing in the live classroom environment (Lambrindis, 2014). In contrast to this, issues brought forth by this approach include ensuring that students have access to a quiet learning environment within their residence or living facilities that allow them to engage properly without any additional distractions. Furthermore, it also requires the student to have proper technology and internet access to tune into the discussion as well. Students also have a limited opportunity to approach the class and or educational material at their own pace given the constraints of a timed meeting engagement (Phungsuk et al, 2014).

For virtual learning environments that are not held within a live meeting time, asynchronous online learning environments provide students with the opportunity to engage with their academic experience at their own pace but within an allotted time frame (Barbour, 2012). This format resembles those observed in online seminars and TedTalk videos, in which the instructor can provide a pre-established learning experience through an informative lecture or review (Martinez-Torres et al, 2006). Benefits brought forth include a lack of a pre-established virtual conference or meeting and students can tend to their classroom obligations, assignments and exams at their own pace and timing within a certain timeframe. Tools such as discussion boards and forums allow students to have a discussion amongst their classmates and instructor(s) at their own pace, by contributing to the topic after getting to review the assigned or pre-established work at their own accord. Negative aspects pertaining to this format of virtual learning environment includes; allowing students the autonomy to finish or cover vital subject information and content necessary to follow the syllabus at their own pace. This could lead to students falling behind or confused if they are not in consultation with their instructors and peers. Therefore, the accountability established in this format of learning environment is further crucial and contingent upon the student than in comparison to other formats.

Lastly, hybridized virtual learning environments are those which combine both the efforts observed in synchronous and asynchronous virtual learning environments can be addressed in hybrid classrooms in which students have the opportunity to engage with class materials on both an online platform as well as in-person (Raij \& Schepers, 2008)

In recent events this has also included those which feature online-video conferencing and discussion platforms such as Zoom and Microsoft Teams. The inclination to utilize hybridized formats of virtual learnings has also brought forth an onslaught of new tools and platforms for students to engage in their education (Chou \& Liu, 2005). The schedule of meeting can also be highly accommodating of different inclement weather situations and safety regulations. 
International Journal on Integrating Technology in Education (IJITE) Vol.10, No.2, June 2021

\begin{tabular}{|c|c|c|}
\hline $\begin{array}{c}\text { Studies observing Asynchronous } \\
\text { virtual learning methods }\end{array}$ & $\begin{array}{c}\text { Studies observing synchronous } \\
\text { virtual learning methods }\end{array}$ & $\begin{array}{c}\text { Studies observing hybrid } \\
\text { learning methods }\end{array}$ \\
\hline $\begin{array}{ll}\text { - } & \text { Martinez-Torres et al, } 2006 \\
\text { - } & \text { Ortega et al, } 2020 \\
\text { - } & \text { Barbour, 2008 } \\
\text { - } & \text { Barbour et al, } 2012 \\
\text { - } & \text { Ruggieri et al, } 2013 \\
\text { - } & \text { Dyson \& Campello, } 2003\end{array}$ & $\begin{array}{ll}\text { - } & \text { Lambrindis, } 2014 \\
\text { - } & \text { Phungsuk et al, } 2014 \\
\text { - } & \text { Rientes et al, } 2013 \\
\text { - } & \text { Ruggieri et al, } 2013\end{array}$ & $\begin{array}{ll}\text { - } & \text { Raij \& Schepers, } \\
& 2008 \\
\text { - } & \text { Chou \& Liu, 2005 } \\
\text { - } & \text { Giesbers et al, 2013 } \\
\text { - } & \text { Maltby\& Mackie, } \\
& 2016\end{array}$ \\
\hline
\end{tabular}

Figure 1: Lists research studies according to learning method format

\section{Conclusion}

Amongst the various articles observed in this study for analysis, as depicted in figure 1. the majority favored an observation of asynchronous virtual learning methods and teaching strategies. Synchronous virtual learning strategies were also noted in terms of their contributions however neither synchronous nor hybrid formats were observed as frequently. The outcomes of the asynchronous studies observed suggested results such as; higher levels of student satisfaction, clustered formatting in learning schedules, the significant impact of connection reliability and instilling practicality in educational efforts (Dyson \& Campello, 2003). In contrast to this, synchronous efforts have brought forth outcomes and concerns such as insufficient time to complete assignments during live meetings, however newfound or unique approaches towards changing routines or structures within synchronous virtual learning environments such as integrating video clips pertaining to different examples on the subject material and providing supplementary e-tools in understanding what the following lecture would be discussing, benefitted student's outlook on synchronous virtual learning efforts that were brought forth (Lambrindis, 2014). Hybridized efforts displayed the benefits that were keen on establishing flexibility for students through a multi-faceted approach (Giesbers et al, 2013).

Researchers often noted that while each approach towards virtual learning environments did cater to students in different manners, user's acceptance of technology and therefore their adoption of the technology itself was contingent upon the ease the technology brought to each demographic's individualized experience and needs as pupils (Jena, 2016). Varying regions of the world display a lack of equity in terms of educational opportunity and accessibility to alternative means in approach (Maltby \& Mackie, 2009). Some schools and or educational institutions cannot afford to provide their students with supplemental tools online for students to seek additional help and practice as they partake in their studies. The budgetary constrictions of different educational systems are often determined by the regions across the globe and the resources made available to them. Amongst the three formats of virtual learning observed, it appears that asynchronous methodologies are those which are inclined to observe increased technology acceptance efforts due to the user's perception of the tools in which they have to engage with it. Especially from a standpoint of autonomy and convenience, by allowing students to approach materials at their own time and pace while still being provided with due dates, consistently noted greater occurrences of engagements amongst users across multiple studies. Overall, the outcome of this reviews suggests that despite each format and approach varying in terms of impact, the varying degree of influence depends upon the type of pre-established in-person learning curriculum that was enacted prior to entering the virtual environment. Nevertheless, as a majority of the research processes favored asynchronous methodologies, it appears that user-based perception and ease are key factors in determining the process and approach towards virtual education dynamics. Moving forward, it would be beneficial to further implore the processes of asynchronous methodologies which best suit student's ease of intake of newfound technologies. It would also be beneficial to further understand how such approaches could better allow educators to 
International Journal on Integrating Technology in Education (IJITE) Vol.10, No.2, June 2021

understand their student's perspective on both their curriculum and relevant technology necessary to access their education, for future endeavors.

\section{REFERENCES}

[1] Ahmed, E., \& Ward, R. (2016). A Comparison of Competing Technology Acceptance Models To Explore Personal, Academic And Professional Portfolio Acceptance Behavior. Journal Of Computers In Education, 3(2), 169-191. Doi:10.1007/S40692-016-0058-1

[2] Bandura, A. (1977). Self-efficacy: Toward a unifying theory of behavioral change. Psychological Review, 84(2), 191-215. doi:10.1037/0033-295x.84.2.191

[3] Barbour, M. (2008). What are they doing and how are they doing it? Rural student experiences in virtual schooling. LearnTechLib.

[4] Barbour, M., Davis, N., \& Wenmoth, D. (2016). Primary and Secondary Virtual Learning in New Zealand: Examining the Process of Achieving Maturity. International Journal on E-Learning, 15(1), 27-45.

[5] Chou, S., \& Liu, C. (2005). Learning effectiveness in a web-based virtual learning environment: A learner control perspective. Journal of Computer Assisted Learning, 21(1), 65-76. doi:10.1111/j.1365-2729.2005.00114.x

[6] Davis, F. D. (1993). User Acceptance Of Information Technology: System Characteristics, User Perceptions And Behavioral Impacts. International Journal Of Man-Machine Studies, 38(3), 475-487. Doi:10.1006/Imms.1993.1022

[7] Dyson, M., \& Barreto, S. (2003). Evaluating Virtual Learning Environments: What Are We Measuring? Electronic Journal of E-Learning, 1, 11-20.

[8] Evans, C., Gibbons, N. J., Shah, K., \& Griffin, D. K. (2004). Virtual learning in the biological sciences: Pitfalls of simply "putting notes on the web". Computers \& Education, 43(1-2), 49-61. doi:10.1016/j.compedu.2003.12.004

[9] Faisal, A., Handayanna, F., \& Purnamasari, I. (2021). Implementation Technology Acceptance Model (Tam) On Acceptance Of The Zoom Application In Online Learning. Jurnal Riset Informatika, 3(2), 85-92. Doi:10.34288/Jri.V3i2.195

[10] Goo, M. K. (2014). The Perceptions of Special Education Teachers on Instructing Using AAC Devices and Special Schools/School District Supports For AAC. Journal of Special Education \& Rehabilitation Science, 53(1). Doi:10.15870/Jsers.2014.03.53.1.115

[11] Hubbard, M., \& Bailey, M. J. (2018). User adoption in teams. Mastering Microsoft Teams, 75-87. doi:10.1007/978-1-4842-3670-3_5

[12] Jena, R. K. (2016). Investigating the interrelation BETWEEN attitudes, learning readiness, and learning styles under virtual learning environment: A study among Indian students. Behaviour\& Information Technology, 35(11), 946-957. doi:10.1080/0144929x.2016.1212930

[13] Keržič, D., Tomaževič, N., Aristovnik, A., \& Umek, L. (2019). Exploring Critical Factors of The Perceived Usefulness of Blended Learning for Higher Education Students. Plos One, 14(11). doi:10.1371/Journal.Pone.0223767

[14] Lambrinidis, G. (2014). Supporting online, non-traditional students through the introduction of effective e-learning tools in a pre-university tertiary enabling programme. Journal of Higher Education Policy and Management, 36(3), 257-267. doi:10.1080/01587919.2014.899053

[15] Lei, J., Calley, S., Brosnan, M., Ashwin, C., \& Russell, A. (2018). Evaluation of a transition to university programme for students with autism spectrum disorder. Journal of Autism and Developmental Disorders, 50(7), 2397-2411. doi:10.1007/s10803-018-3776-6

[16] Maltby, A., \& Mackie, S. (2009). Virtual learning environments - help or hindrance for the 'disengaged' student? ALT-J,17(1), 49-62. doi:10.1080/09687760802657577

[17] Ohk, K., Park, S., \& Hong, J. (2015). The Influence of Perceived Usefulness, Perceived Ease Of Use, Interactivity, And Ease Of Navigation On Satisfaction In Mobile Application. Doi:10.14257/Astl.2015.84.18

[18] Ortega, P., Shin, T. M., Pérez-Cordón, C., \& Martínez, G. A. (2020). Virtual medical spanish education at the corazón of hispanic/latinx health during covid-19. Medical Science Educator, 30(4), 1661-1666. doi:10.1007/s40670-020-01058-0 
International Journal on Integrating Technology in Education (IJITE) Vol.10, No.2, June 2021

[19] Owusu-Mensah, F. (2019). Distance Education Students' Use of Activities in Their Self-Instructional Modules: The Case Of Distance Education Students Of The University Of Education, Winneba, Ghana. Education Quarterly Reviews, 2(4). Doi:10.31014/Aior.1993.02.04.104

[20] Pal, D., \&Vanijja, V. (2020). Perceived Usability Evaluation of Microsoft Teams As An Online Learning Platform During Covid-19 Using System Usability Scale And Technology Acceptance Model In India. Children And Youth Services Review, 119, 105535. Doi:10.1016/J.Childyouth.2020.105535

[21] Phungsuk, R., Viriyavejakul, C., \& Ratanaolarn, T. (2017). Development of a problem-based learning model via a virtual learning environment. Kasetsart Journal of Social Sciences, 38(3), 297-306. doi:10.1016/j.kjss.2017.01.001

[22] Rienties, B., Giesbers, B., Lygo-Baker, S., Ma, H. W., \& Rees, R. (2014). Why some teachers easily learn to use a new virtual learning environment: A technology acceptance perspective. Interactive Learning Environments, 24(3), 539-552. doi:10.1080/10494820.2014.881394

[23] Rovai, A. P., \& Ponton, M. K. (2019). AN examination of sense of classroom community and learning Amongafrican American and CAUCASIAN graduate students. Online Learning, 9(3). doi:10.24059/olj.v9i3.1786

[24] Tagoh, M., \& Abakah, E. (2014). "Determining Distance Education Students' Readiness for Mobile Learning at University of Ghana Using The Theory Of Planned Behavior". International Journal of Education and Development Using Information and Communication Technology, 10(1), 99-106.

[25] Teo, T. (2011). Technology Acceptance Research in Education. Technology Acceptance in Education, 1-5. Doi:10.1007/978-94-6091-487-4_1

[26] Tolma, E. L., Reininger, B. M., Evans, A., \& Ureda, J. (2006). Examining the Theory of Planned Behavior and The Construct of Self-Efficacy to Predict Mammography Intention. Health Education \& Behavior, 33(2), 233-251. Doi:10.1177/1090198105277393

[27] Van Walraven, C., Wong, J., \& Forster, A. J. (2013). Influence of Neighborhood Household Income on Early Death or Urgent Hospital Readmission. Journal of Hospital Medicine, 8(5), 261-266. Doi: $10.1002 / \mathrm{Jhm} .2025$

[28] Van Raaij, E. M., \& Schepers, J. J. (2008). The acceptance and use of a virtual learning environment in China. Computers \& Education, 50(3), 838-852. doi:10.1016/j.compedu.2006.09.001

[29] Venkatesh, Morris, Davis, \& Davis. (2003). User Acceptance of Information Technology: Toward A Unified View. Mis Quarterly, 27(3), 425. Doi:10.2307/30036540

[30] Whoriskey, M. (2003). Progress with Learning Disability Hospital Closures in Scotland. Tizard Learning Disability Review,8(1), 4-9. Doi:10.1108/13595474200300002

\section{AUTHORS}

Munther Abualkibash is an assistant professor and graduate coordinator within the Eastern Michigan University College of Technology. His interests and expertise include computer and network security, cloud computing, machine learning and parallel and distributed systems. He received his master's degree from the University of Bridgeport, in Bridgeport, Connecticut. There, he also earned his Ph.D. in computer science and engineering.

Tasfia Bari is a PhD candidate and graduate research assistant in Eastern Michigan University's College of Technology. She earned her Bachelor of Science at Eastern Michigan University in Ypsilanti, Michigan. She has graduate research experience throughout her time in the College of Technology as both a master's and Doctoral candidate. She is currently working towards earning her $\mathrm{PhD}$ while conducting research as a graduate assistant under the supervision of Dr. Munther Abualkibash. 